\title{
Does Parental Divorce Increase Risk Behaviors among 15/16 and 18/19 year-old Adolescents? A Study from Oslo, Norway
}

\author{
Henok Zeratsion ${ }^{1, *}$, Cecilie B. Bjertness ${ }^{1}$, Lars Lien ${ }^{2}$, Ole R. Haavet ${ }^{3}$, Madeleine Dalsklev ${ }^{4}$, \\ Jon A. Halvorsen ${ }^{5}$, Espen Bjertness ${ }^{1,6}$ and Bjørgulf Claussen ${ }^{1}$
}

\author{
${ }^{1}$ Institute of Health and Society, University of Oslo, Box 1130 Blindern, 0318 Oslo, Norway; ${ }^{2}$ National Center for Dual \\ Diagnoses, Innlandet Hospital Trust HF 2312 Ottestad, Norway; ${ }^{3}$ Department of General Practice, Institute of Health \\ and Society, University of Oslo, Norway; ${ }^{4}$ Institute of Psychology, University of Oslo, Box 1130 Blindern, 0318 Oslo, \\ Norway; ${ }^{5}$ Department of Dermatology, Oslo University Hospital Rikshospitalet, Faculty of Medicin, Norway; ${ }^{6}$ Tibet \\ University Medical College, Lhasa, Tibet, China
}

\begin{abstract}
Background: Several studies have reported an increase in risk behaviors among adolescents after experience of parental divorce. The aim of the study was to investigate whether parental divorce is associated with risk behavior among adolescents independent of mental health problems, first when early divorce was experienced, and second after experience of late parental divorce. Method: One prospective $(\mathrm{n}=1861)$ and one cross-sectional study $(\mathrm{n}=2422)$ were conducted using data from two Young-HUBRO surveys in Oslo, Norway. All 15/16 year-old $10^{\text {th }}$ grade students who participated in the first survey in the school year 2000/01 were followed-up in 2004 when they were 18/19 year-olds. The follow-up rate was $68 \%$. The prospective study investigated the influence of late parental divorce that occurred between the age of $15 / 16$ and 18/19. In the cross-sectional study we focused on early parental divorce that occurred before the participants were $15 / 16$ year-old. Results: In the prospective study we could not discern a significant association between experiencing late parental divorce and an increase in risk behaviors among 18/19 year-old adolescents. In the cross-sectional study parental divorce was significantly associated with cigarette smoking and using doping agents. Conclusion: Parental divorce that occurs when the children of divorced parents are 15/16 year-old or younger is associated with an increase in cigarette smoking and use of doping agents. However, no evidence of significant association is found between experience of late parental divorce and risk behaviors in late adolescence.
\end{abstract}

Keywords: Adolescents, internalized and externalized mental health problems, parental divorce, risk behaviors.

\section{INTRODUCTION}

Experiencing parental divorce has been associated with an increased likelihood of exhibiting psychological, behavioral and social problems among children of divorced parents [1-4]. Several prospective and cross-sectional studies among adolescents found that an increase in risk behaviors including cigarette smoking, alcohol intake and substance abuse was associated with experience of parental divorce [5-10]. However, some studies reported that the adverse effect of parental divorce was found only among boys and not among girls $[11,12]$.

A longitudinal study from the USA found that adolescents who experienced parental divorce in their early or late adolescence had higher rates of cigarette smoking when compared with their peers from continuously married parents [3]. According to a Norwegian study [4] and three European studies $[6,7,13]$, adolescents who lived with both parents drank less $[10,14]$ and smoked less cigarettes $[15]$ than their peers who lived in other types of families. In investigations of the long-term effect of parental divorce, alcohol

\footnotetext{
*Address correspondence to this author at the Institute of Health and Society, University of Oslo, Box 1130 Blindern, 0318 Oslo, Norway; Tel: +47 4128 3758; Fax: +47 2285 0610;

E-mails: h.t.zeratsion@medisin.uio.no or hzeratsion@yahoo.com
}

consumption was found to be significantly higher among adults [16] and women [17] who experienced parental divorce during childhood or adolescence than among their counterparts without such experience. Parental divorce during childhood or adolescence was found to have been significantly associated with lifetime alcohol dependence $[9$, $10,18]$.

There is an indication of an indirect effect on risk behaviors of parental divorce that is mediated by mental health problems. In a study from Norway, there was an evidence of significant effect of parental divorce on the offspring's mental health problem [19] which in turn was associated with cigarette smoking, alcohol consumption and illicit substance use in children and adolescents [20]. In our previous prospective study of the same study population, however, we found non-significant association between experience of late parental divorce and mental health problems among young people in their late adolescence [21].

It seems that there are few empirical studies that have examined several risk behaviors at the same time among adolescents of divorced parents. The present study is expected to contribute towards addressing this scarcity in literature by investigating the association of parental divorce with four types of risk behaviors including cigarette smoking, snus 
use, frequent alcohol drinking, and use of doping agents. Public health implications of parental divorce also make the present study timely. A previous research elucidated a considerable public health effect when it found an increased risk for cancer at tobacco-related and alcohol-related sites among 0-70 year-old offspring of divorce [22].

We wanted to test two hypotheses with two designs:

1. Compared to their peers from continuously married parents, 18/19 year-old adolescents have higher risk for increased risk behaviors after experience of late parental divorce that occur between 15/16 and 18/19 years of age (the prospective study).

2. Adolescents experiencing parental divorce when they are $15 / 16$ year-old or younger have higher level of risk behaviors compared with their peers whose parents were continuously married at $15 / 16$ years of age (the crosssectional study).

\section{MATERIALS AND METHODOLOGY}

\section{Data Source and Selection of participants}

All members in a cohort of $15 / 16$ years-old $10^{\text {th }}$ grade students in the city of Oslo $(\mathrm{n}=4273)$ were invited to participate in the baseline survey of Young-HUBRO in their school-year 2000/2001, and were followed-up three years later. The response rate at the baseline and follow-up surveys was $89 \%(\mathrm{n}=3811)$ and $68 \%$, respectively. Additional description of sampling in Young-HUBRO is available in another article [23].

Self-administered questionnaires were primarily answered in class room sessions. The questionnaire was sent by post to $13 \%$ of the participants who were not present at school at follow-up. Participants who stated parental marital status was other than married/cohabitants or divorced/separated in the first survey $(\mathrm{n}=191)$ and those who stated inconsistent response in both surveys $(n=55)$ were not relevant for our study objective and were excluded from analysis, giving a new baseline sample of Young-HUBRO $(\mathrm{n}=3565)$. Among these, 1143 adolescents did not respond to the question on marital status giving a usable sample of 2422 for the cross-sectional study. Since our focus was on late parental divorce in the prospective study, we excluded the 530 adolescents who had experienced parental divorce before the age of 15/16 years and other 31 adolescents whose parental marital status at follow-up was other than mar$\mathrm{ried} /$ cohabitant or divorced/separated, giving a sample of 1861.

\section{Explanatory Variables}

Dichotomized into "continuously married" and "divorced", parental marital status was our main independent variable. Continuously married was defined as parents of adolescents who had never experienced divorce until time of study in 2000/01 for cross-sectional study, and in 2004 for prospective study. Divorce that occurred between the two surveys was termed "late parental divorce" while "early parental divorce" was defined as all parental divorces that occurred when the offspring was $15 / 16$ year-old or younger.
Potential confounders included gender, ethnicity, family economy, social support, and internalized or externalized mental health problems. Ethnicity was dichotomized into "western" and "non-western" based on parents' place of birth. Family economy was dichotomized into "above average" and "average and below", based on the statement "I believe, relative to others in Norway, my family has: 1) 'poor economy', 2) 'average economy'; 3) 'good economy'; or 4) 'very good economy'." Social support was created by summarizing the response of two questions that focused on availability of help: "How many persons outside your immediate family are so close to you that you can rely on to get help 1) if you have personal problems, 2) if you have practical problems (for example, school assignments)?" Those who answered " 0 " or " 1 " for each of these two separate questions formed the low social support category, and the rest were grouped to form the high social support category. This gave a cut-off point at $85^{\text {th }}$ and $78^{\text {th }}$ percentile of the sample in the first and the second question, respectively. The mean inter-item correlation value was 0.42 , which is within an optimal range for a scale with fewer than 10 items [24]. The number of people to rely on for help was used as a proxy measure of social support as in other studies [25].

Internalized mental health problems were measured using the 10-item version of the Hopkins Symptoms Check List (HSCL-10). The ten questions were asked to measure the level of anxiety and depression symptoms during the week preceding the date of survey. Ten items were rated on a scale from 1 (no symptom) to 4 (much of the symptom). An average score for all 10 -items of 1.85 was used as cut-off point to dichotomize the variable into "No internal mental health problem" and "Have internal mental health problem"; the second category was formed of scores greater than or equal to 1.85 [26]. This cut-off point was used in other studies as a valid predictor of mental distress among adolescents [27]. Reliability was high (Cronbach's alpha $=0.88$ ).

Externalized mental health problems were measured by the 10 items of hyperactivity and conduct problems in the Strengths and Difficulties Questionnaire [27, 28]. The study participants answered as "not true" (0), "somewhat true" (1) or "certainly true" (2), to the statements in each of the 10 items which gave scores from 0 to 20 . The period of six months preceding the survey date was the reference period for self-reporting on externalized mental health. The cut-off point was set at $90^{\text {th }}$ percentile of the sample as in other studies $[27,29]$. This dichotomized the variable into "no externalized mental health problem" $(0)$ and "have externalized mental health problem" (1). Reliability was alpha $=0.67$.

\section{Outcome Variables: Risk Behaviors}

In the present study, risk behavior refers to life style actions related to the consumption or abuse of cigarettes, snus, alcohol or doping agents. Each of these four risk behaviors was studied separately as an outcome variable.

\section{Cigarette Smoking}

The question was "Do you smoke, or have you smoked?" The response categories 'Never', and 'Yes, but I have stopped' were recoded as "no"; and the remaining response categories 3) 'Yes, sometimes' and 4) 'Yes, every day' were 
recoded as "yes". For quitters, we did not have data on the time they stopped smoking. Therefore, we could not know whether smoking was quitted before or after parental divorce occurred; thus, quitters were categorized in the non-smoker group.

\section{Snus}

The variable "snus" was primarily used to describe the moist powder tobacco placed under the lips and which does not need for spitting. It is common in the Scandinavian region. As the question read "Do you use or have you used snus or the likes?", in addition to snus consumption, the variable also refers to other tobacco forms consumed in the mouth or those snuffed through the nose. The response categories 'Never' and 'Yes, but I have stopped' were recoded as "no"; and 'Yes, sometimes' and 'Yes, every day' were recoded as "yes". Due to lack of data on time they stopped using snus, those who quitted using snus or its variants were grouped with respondents who had never used snus.

\section{Frequency of Drinking}

The question was "Approximately how often, during the last year, have you been drinking alcohol?" The response categories '4-7 times a week,' '2-3 times a week, and 'approximately once a week' were recoded as "yes"; and the remaining categories '2-3 times a month,' 'Approximately once a month,' 'A few times last year,' 'Did not drink alcohol last year', and 'Have never had alcohol' were recoded as "no".

\section{Doping Agents}

The question was "Have you used doping agents?" The response category 'Never' was recoded as "no", and the response categories 'Yes, once', 'Yes, sometimes' and 'Yes, I use it regularly' were recoded as "yes".

\section{Missing Values}

In our present cross-sectional study the sample included only those who participated in both waves of YoungHUBRO survey and who answered the question on parental marital status. The missing values were in $32 \%$ of the participants $(n=3565)$ in the first Young-HUBRO survey. The proportion of non-response was lower (27\%) among western than among non-western (42\%) adolescents. The missingness of response was random at the other independent variables.

\section{Statistics}

Pearson's chi square test was used to study bivariate associations of parental divorce with other explanatory variables (Table 1) and with outcome variables (Table 2). We fitted multivariate logistic regression models in a prospective (Table 3) and a cross-sectional (Table 4) study to analyze the impact of parental divorce on the risk behavior variables. Only one risk behavior was included as a dependent variable in each statistical model.

In the prospective study we analyzed the relation between late parental divorce and a change in risk behavior over the follow-up period of three years. Taking the risk behavior at age $18 / 19$ as the outcome variable, we controlled for gender, ethnicity, family economy, social support, mental health problems and the same risk behavior at age 15/16. Adjusting for cigarette smoking at age 15/16, for example, we investigated if the increase in the odds of cigarette smoking from baseline to follow-up was higher among adolescents who experienced late parental divorce than among their counterparts from continuously married parents, independent of cigarette smoking at baseline. Thus, the dependent variable in the prospective study was made to be the change in the odds of cigarette smoking in relation to a change in parental marital status during the follow-up time.

In the cross-sectional study, the odds of developing a risk behavior among 15/16 year-old adolescents who experienced parental divorce before age 15/16 was compared with that of peers from continuously married parents. In addition to the other independent variables, either internalized- or externalized mental health problem was controlled for in all regressions.

\section{Ethics}

Both the students and their parents gave their informed consents. The study was approved by the Regional Committee for Medical Research Ethics in South East Norway.

\section{RESULTS}

In the prospective study, $5.9 \%$ of the adolescents had experienced parental divorce between 15/16 and 18/19 years of age, while in the cross-sectional study, $21.9 \%$ had experienced parental divorce when they were $15 / 16$ year-old or younger.

Late parental divorce was associated with family economy and with internalized mental health problems (Table 1). Early parental divorce was more often experienced among western children and adolescents, those reporting average and low family economy, or internalized mental health problems.

Neither crude nor adjusted results showed significant association of late parental divorce with increase in odds of risk behaviors over the follow-up period (Table 3). Adjustment for mental health problems did not change this non-significant association. In the cross-sectional design, crude OR showed significant association of parental divorce with risk of cigarette smoking and using doping agents (Table 4). This significant association sustained even when the model was adjusted for gender, ethnicity, family economy, social support and internalized or externalized mental health problems.

\section{DISCUSSION}

In our prospective study we found no evidence of significant change in the odds of risk behaviors after experience of late parental divorce between 15/16 and 18/19 years of age. In the cross-sectional study it was found that $15 / 16$ year-old adolescents who experienced early parental divorce were more likely to smoke cigarettes and use doping agents compared to their peers whose parents were continuously married.

Thus, we do not have evidence from the prospective study to support our first hypothesis of an increase in risk behaviors after late parental divorce. Our second hypothesis of higher levels of cigarette smoking and use of doping agents among 15/16 year-olds who experienced parental divorce before they were 15/16 year-old has been supported by the results of the cross-sectional study. 
Table 1. Independent variables (vertical percentages) across late parental divorce experienced between 15/16 and 18/19 years of age $(n=109)$ in a prospective study, and across early divorce experienced before the adolescent became 15/16 year-old $(n=530)$ in a cross-sectional study of 18/19 year-old norwegian adolescents in 2004.

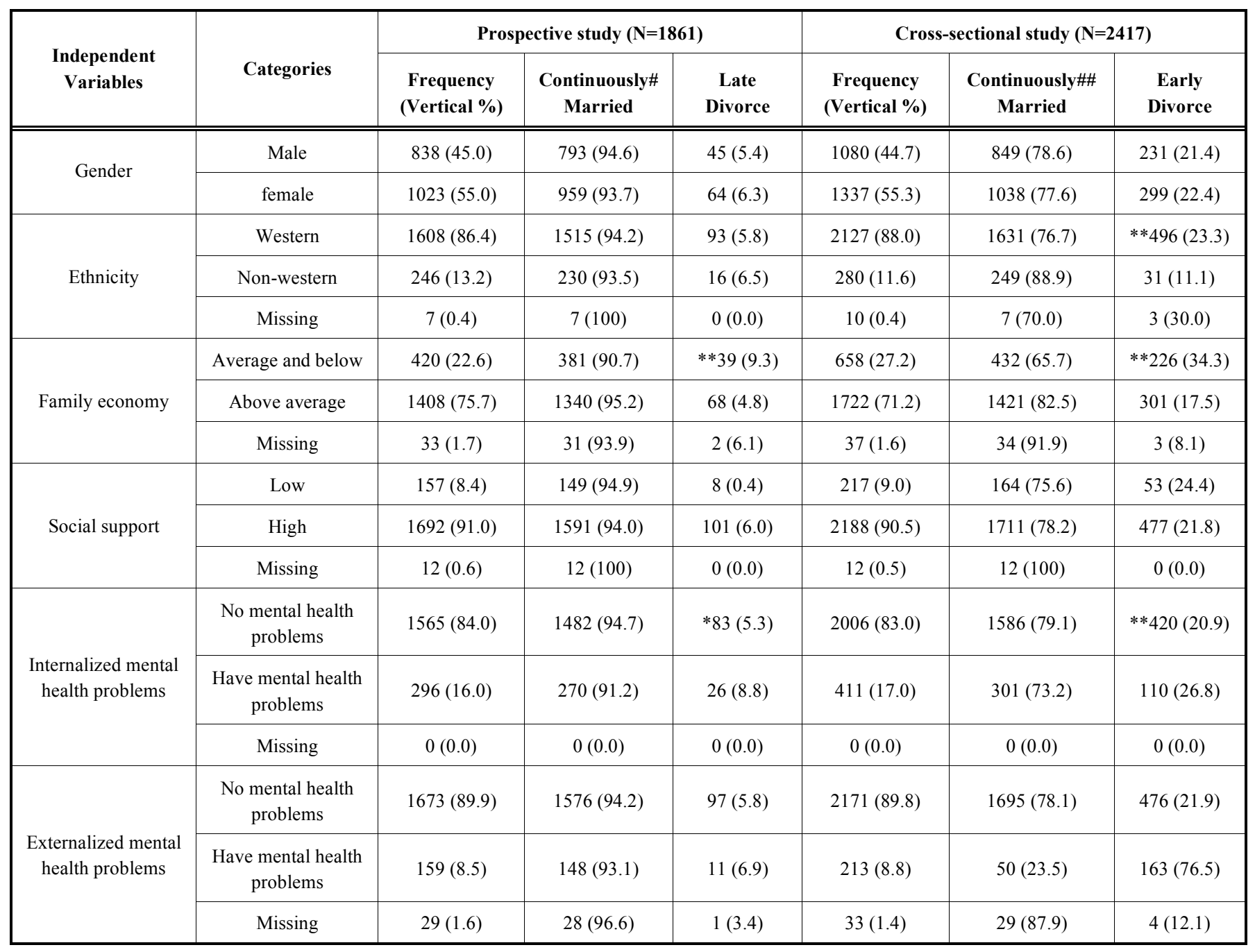

Significant association at $* *(\mathrm{p}<0.01)$ or $*(\mathrm{p}<0.05)$. \#Parents continuously married until follow-up time. \#\#Parents continuously married until time of first survey.

The results of our cross-sectional study are consistent with findings from previous cross-sectional studies $[3,7,9$, $14,15]$ and prospective studies $[5,12]$. A study from Norway has reported that regular smoking and use of illegal drugs were found to be more common among boys and girls of divorced parents than their counterparts living with both biological parents [8]. Our findings show that early parental divorce continues to have significant impact on adolescents' risk behaviors even when divorce rate in recent years is higher than before. For example, the divorce rate was 17.5 per 1000 married status in 2001 as compared to only 9.5 per 1000 married couples in the age group 35 55 in 1984 [30]. Using data collected in 1984/86, a significant adverse influence of parental divorce was previously found in Norway [31].

There is a possibility for an indirect influence on risk behaviors of experience of parental divorce mediated by mental health problems. Several studies have found significant association between experience of parental divorce and mental health problems $[19,32,33]$, which in turn was found to be associated with risk behaviors including cigarette smoking, alcohol consumption and illicit substance use [20]. Stated more precisely, parental divorce increases the likelihood of risk behaviors by increasing mental health problems in adolescents [3]. Both of the present study designs also show that mental health problems observed when the adolescents were 15/16 year-old were associated with several risk behaviors. However, we did not find statistically significant association between experience of late parental divorce and mental health problems in our previous prospective study of the same study population [21]. Thus, the non-significant association between late parental divorce and risk behaviors in our present prospective study was not unexpected.

Additional possible explanations for the non-significant association in our prospective study may be related to the time of occurrence of parental divorce. Some studies have reported that risk behaviors among offspring of divorce are related to the offspring's age at the time of parental divorce [34-36]. Whereas elementary school boys who experienced 
Table 2. Risk behavior across late parental divorce experienced between 15 and 19 years of age in the prospectively studied sample of 18/19 year-old adolescents in oslo in 2004 (vertical percentages).

\begin{tabular}{|c|c|c|c|c|}
\hline Outcome Variables & Categories & $\begin{array}{l}\text { Frequency (Vertical \%) } \\
\qquad \mathbf{n}=\mathbf{1 8 6 1}\end{array}$ & $\begin{array}{c}\text { Continuously Married } \\
\qquad \mathbf{n}=1752\end{array}$ & $\begin{array}{l}\text { Late Divorce } \\
\qquad \mathbf{n}=109\end{array}$ \\
\hline \multirow{3}{*}{ Cigarette smoking } & Yes & $644(34.6)$ & $598(34.1)$ & $46(42.2)$ \\
\hline & No & $1213(65.2)$ & $1150(65.6)$ & $63(57.8)$ \\
\hline & Missing & $4(0.2)$ & $4(0.3)$ & $0(0.0)$ \\
\hline \multirow[t]{2}{*}{ Snus } & No & $1500(80.6)$ & $1410(80.5)$ & $90(82.6)$ \\
\hline & Missing & $3(0.2)$ & $3(0.2)$ & $0(0.0)$ \\
\hline Frequency of drinking & At least once a week & $735(39.5)$ & $691(39.4)$ & $44(40.4)$ \\
\hline \multirow[t]{2}{*}{ Doping agents } & Never & $1715(92.2)$ & $1614(92.1)$ & $101(92.7)$ \\
\hline & Missing & $4(0.2)$ & $4(0.3)$ & $0(0.0)$ \\
\hline
\end{tabular}

Significance level was set at $\mathrm{p}$-value $=0.05$ and no statistically significant association was found.

Table 3. Late parental divorce experienced between 15 and 19 years of age $(n=109)$ with change in risk behaviors in a prospective study of $18 / 19$ year-old adolescents $(n=1861)$ when odds ratios $(95 \%$ confidence interval) were adjusted in logistic regressions for the same risk behavior, demographic, socio-economic and mental health problem variables observed at the age of 15/16.

\begin{tabular}{|c|c|c|c|c|}
\hline \multicolumn{5}{|c|}{ Crude results } \\
\hline \multicolumn{5}{|c|}{ Adjusted for internalized mental health problems } \\
\hline Gender (ref=boys) & $0.8(0.6-1.0)$ & $0.2(0.1-0.3)$ & $0.8(0.6-1.0)$ & $0.9(0.6-1.2)$ \\
\hline Ethnicity (ref=western) & $0.8(0.6-1.2)$ & $0.4(0.2-0.6)$ & $0.4(0.2-0.7)$ & $1.1(0.7-2.0)$ \\
\hline Family economy (ref=average and below) & $0.9(0.7-1.2)$ & $1.6(1.1-2.3)$ & $1.5(1.1-2.0)$ & $1.3(0.9-2.0)$ \\
\hline Social support (ref=low) & $0.9(0.6-1.4)$ & $1.2(0.7-1.9)$ & $1.2(0.8-1.9)$ & $0.9(0.5-1.8)$ \\
\hline Late parental divorce (ref=continuously married) & $1.2(0.8-2.0)$ & $1.1(0.6-1.9)$ & $0.9(0.6-1.5)$ & $1.0(0.5-2.2)$ \\
\hline Gender (ref=boys) & $0.8(0.6-1.0)$ & $0.2(0.1-0.3)$ & $0.8(0.6-1.0)$ & $1.0(0.7-1.5)$ \\
\hline Ethnicity (ref=western) & $0.8(0.6-1.1)$ & $0.4(0.2-0.7)$ & $0.4(0.3-0.7)$ & $1.3(0.6-1.9)$ \\
\hline Family economy (ref=average and below) & $0.9(0.7-1.2)$ & $1.6(1.1-2.3)$ & $1.4(1.1-1.9)$ & $1.3(0.8-2.1)$ \\
\hline Social support (ref=low) & $1.0(0.7-1.5)$ & $1.1(0.7-1.9)$ & $1.2(0.8-1.9)$ & $1.0(0.5-2.0)$ \\
\hline Externalized problems $(\mathrm{ref}=\mathrm{no})$ & $1.6(1.1-2.3)$ & $1.6(1.1-2.5)$ & $0.9(0.6-1.4)$ & $2.1(1.2-3.4)$ \\
\hline
\end{tabular}


Table 4. Early parental divorce experienced when the adolescents were 15/16 year-old or younger (n=530) across risk behaviors in a cross-sectional study of $15 / 16$ year-old adolescents $(n=2422)$ when odds ratios $(95 \%$ confidence interval) were adjusted for demographic, socio-economic and mental health variables.

\begin{tabular}{|c|c|c|c|c|}
\hline \multicolumn{5}{|c|}{ Crude results } \\
\hline \multicolumn{5}{|c|}{ Adjusted for internalized mental health problems } \\
\hline Early parental divorce (ref=continuously married) & $1.3(1.1-1.6)$ & $1.0(0.7-1.4)$ & $1.2(0.9-1.5)$ & $1.6(1.2-2.2)$ \\
\hline Ethnicity (ref=western) & $0.6(0.4-0.9)$ & $0.3(0.1-0.7)$ & $0.7(0.4-1.2)$ & $0.7(0.4-1.2)$ \\
\hline Family economy (ref=average and below) & $1.0(0.8-1.2)$ & $1.3(0.9-2.0)$ & $1.9(1.5-2.5)$ & $1.2(0.9-1.7)$ \\
\hline Social support (ref=low) & $0.8(0.6-1.1)$ & $1.2(0.7-2.2)$ & $1.1(0.8-1.7)$ & $0.7(0.4-1.1)$ \\
\hline Gender (ref=boys) & $1.6(1.3-1.9)$ & $0.4(0.2-0.7)$ & $1.3(1.1-1.6)$ & $1.2(0.9-1.7)$ \\
\hline Ethnicity (ref=western) & $0.6(0.4-0.9)$ & $0.3(0.1-0.7)$ & $0.7(0.4-1.2)$ & $0.7(0.4-1.3)$ \\
\hline Family economy (ref=average and below) & $1.0(0.8-1.2)$ & $1.4(0.9-2.1)$ & $1.9(1.4-2.5)$ & $1.2(0.9-1.7)$ \\
\hline Social support (ref=low) & $0.8(0.6-1.1)$ & $1.3(0.7-2.4)$ & $1.2(0.8-1.7)$ & $0.7(0.5-1.4)$ \\
\hline Externalized problems $(\mathrm{ref}=\mathrm{no})$ & $3.0(2.3-4.2)$ & $2.4(1.5-3.8)$ & $2.3(1.7-3.3)$ & $5.2(3.6-7.4)$ \\
\hline
\end{tabular}

parental divorce were likely to develop problem behaviors later in their adolescence ages, the effect of parental divorce on adolescents in middle school was found to be less enduring [34]. Similarly, heavy drinking was found to be more common among 22 year-old who experienced parental divorce between age 7 and 12 than among their peers who had similar experience during their adolescence [35]. The extent of smoking and drinking was higher among 17 year-old adolescents who resided at age 12 in families where at least one biological parent was not present than those who lived with both biological parents in their early adolescence [36]. Even studies conducted a few decades ago provide evidence that the adverse effects of parental divorce are larger for children who were very young at the time of their parents' marital dissolution than for children who encounter a relatively late parental divorce [37]. All these studies indicate that early parental divorce has greater negative effect than late parental divorce. A possible explanation could be the fact that key transitional points in the lives of young people occur between ages 13 and 14 during which there is greater tendency to begin or increase the consumption of alcohol, tobacco and illicit drug [38]. A decrease in parenting effectiveness due to parental absence following divorce [1] at the critical ages of early adolescence where there is a tendency to begin cigarette smoking, drinking and substance use [36] seem to explain the significant impact of early parental divorce. Thus, the findings in our present study might have been to a certain extent influenced by the time of the occurrence of parental divorce in the lifespan of the offspring.

\section{STRENGTHS AND LIMITATIONS}

Data are from a prospective follow-up of a population with $89 \%$ participation at the first survey and a $68 \%$ followup rate three years later. Unlike estimates of prevalence, association measures are shown to be robust to a loss-tofollow-up of $32 \%$ as in the present study [23]. The divorce rate in Norway was $5.3 \%$ of those in married status over the follow-up period in the age group 35-55 [30]. Our sample was representative of Norway because this rate is similar to the $5.9 \%$ computed in our study.

Missing data was more common among non-western than among western adolescents making our estimates to be more unsecure for ethnic non-Norwegians. Furthermore, a low rate of late parental divorce during the three years of follow-up gives us no indications of divorce being a cause of change in risk behavior. This low rate gave a small sample size of adolescents with experience of late parental divorce $(n=109)$ which might have rendered difficulty to discern the significance of associations between late parental divorce and risk behaviors in our prospective study.

We did not have data on the adolescents' age when divorce occurred. Because of this we could not investigate association of parental divorce that occurred at different ages with risk variables at 18/19 years of age.

\section{CONCLUSION}

Our prospective study could not show that parental divorce in late adolescence increase risk behavior among 18/19 
year-old adolescents. In our cross-sectional study, parental divorce experienced during childhood or early adolescence is found to be associated with cigarette smoking and use of doping agents among 15/16 year-old adolescents.

\section{CONFLICT OF INTEREST}

The authors confirm that this article content has no conflict of interest.

\section{AUTHORS' CONTRIBUTIONS}

All authors decided design and methods, $\mathrm{HZ}$ did the analysis and wrote the manuscript drafts, all authors read and approved the final manuscript, and $\mathrm{BC}$ supervised the work.

\section{ACKNOWLEDGEMENTS}

We thank the National Institute of Public Health for providing data, and Oslo Municipality for supporting the Young-HUBRO study.

\section{REFERENCES}

[1] Amato PR, Keith B. Parental divorce and the well-being of children: a meta-analysis. J Marriage Family 1991; 53: 43-58.

[2] Amato PR. Children of divorce in the 1990s: an update of the Amato and Keith (1991) meta-analysis. J Fam Psychol 2001; 3: 355-70.

[3] Kirby JB. The influence of parental separation on smoking initiation in adolescents. J Health Soc Behav 2002; 43: 56-71.

[4] Nævdal F, Thuen F. Residence arrangements and well-being: A study of Norwegian adolescents. Scand J Psychol 2004; 45: 363 71.

[5] Fergusson DM, Horwood LJ, Lynskey MT. Parental separation, adolescent psychopathology, and problem behaviors. J Am Acad Child Adolescent Psychiatry 1994; 33: 1122-33.

[6] Bjarnason T. Andersson B, Choquet M, Elekes Z, Morgan M, Rapinett G. Alcohol culture, family structure and adolescent alcohol use: multilevel modelling of frequency of heavy drinking among 15-16 year-old students in 11 European countries. J Stud Alcohol Drugs 2003, 64: 200-8.

[7] Bjarnason T, Davidaviciene AG, Miller P, Nociar A, Pavlakis A, Sterger E. Family structure and adolescent cigarette smoking in eleven European countries. Society for the Study of Addiction to Alcohol and Other Drugs 2003; 98: 815-24.

[8] Breivik K, Olweus D. Children of divorce in a Scandinavian welfare state: are they less affected than US children? Scand J Psychol 2006; 1: 61-74.

[9] Roustit C, Chaix B, Chauvin P. Family breakup and adolescents' psychosocial maladjustment: public health implications of family disruptions. Paediatrics 2007; 120: 984-91.

[10] Huurre T, Lintonen T, Kaprio J, Pelkonen M, Marttunen M, Aro H. Adolescent risk factors for excessive alcohol use at age 32 years: a 16-year prospective follow-up study. Soc Psychiatry Psychiatr Epidemiol 2010; 1: 125-34.

[11] Needle RH, Su SS, Doherty WJ. Divorce, remarriage and adolescent substance abuse: a prospective longitudinal study. J Marriage Fam 1990; 52: 157-69.

[12] Doherty WJ, Needle RH. Psychological adjustment and substance use among adolescents before and after a parental divorce. Child Dev 1991; 62: 328-37.

[13] Griesbach D, Amos A, Currie C. Adolescent smoking and family structure in Europe. Soc Sci Med 2003; 56: 41-52.

[14] Thompson RG Jr, Lizardi D, Keyes KM, Hasin DS. Childhood or adolescent parental divorce/separation, parental history of alcohol problems, and offspring lifetime alcohol dependence. Drug Alcohol Depend 2008; 3: 264-9.
[15] Anda RF, Croft J B, Felitti VJ, et al. Adverse childhood experiences and smoking during adolescence and adulthood. JAMA 1999; 282: 1652-58.

[16] Rothman EF, Edwards EM, Heeren T, Hingson RW. Adverse childhood experiences predict earlier age of drinking onset: results from a representative US sample of current or former drinkers. Paediatrics 2008; 2: e298-304.

[17] Kuh D, Maclean M. Women's childhood experience of parental separation and their subsequent health and socio-economic status in adulthood. J Biosoc Sci 1990; 22: 121-35.

[18] Hasin DS, Thompson RG, Lizardi D, and Keyes KM. Childhood or adolescent parental divorce/separation, parental history of alcohol problems, and offspring lifetime alcohol dependence. Drug Alcohol Depend 2008; 98: 264-69.

[19] Størksen I, Røysamb E, Moum T, Tambs K. Adolescents with a childhood experience of parental divorce: a longitudinal study of mental health and adjustment. J Adolescence 2005; 28: 725-35.

[20] Kandel BD, Johnson JG, Bird HR, et al. Psychiatric disorders associated with substance use among children and adolescents: findings from the methods for the epidemiology of child and adolescent mental disorders (MECA) study. J Abnorm Child Psychol 1997; 25: 121-32.

[21] Zeratsion H, Dalsklev M, Bjertness E, et al. Parental divorce in late adolescence does not seem to increase mental health problems: a population study from Norway. BMC Public Health 2013; 13: 413.

[22] Hemminki K, Chen B. Lifestyle and cancer: effect of parental divorce. Eur J Cancer Prev 2006; 6: 524-30.

[23] Bjertness E, Sagatun $\AA$, Green K et al. Response rates and selection problems, with emphasis on mental health variables and DNA sampling, in large population-based, cross-sectional and longitudinal studies of adolescents in Norway. BMC Public Health 2010; 10: 602 .

[24] Briggs SR, Cheek JM. The role of factor analysis in the development and evaluation of personality scales. J Pers 1986; 54: 106-48.

[25] Schraedley PK, Gotlib IH, Hayward C. Gender differences in correlates of depressive symptoms in adolescents. J Adolesc Health 1999; 25: 98-108.

[26] Strand BH, Dalgard OS, Tambs K, Rognerud M. Measuring the mental health status of the Norwegian population: a comparison of the instruments SCL-25, SCL-10, SCL-5 and MHI-5 (SF-36). Nord J Psychiatry 2003; 57: 113-8.

[27] Lien L, Haavet OR, Thoresen M, Heyerdahl S, Bjertness E. Mental health problems, negative life events, perceived pressure and the frequency of acute infections among adolescents: results from a cross-sectional, multicultural, population-based study. Acta Pædiatrica 2007; 96: 301-6.

[28] Goodman R. Psychometric properties of the strengths and difficulties questionnaire. J Am Acad Child Adolesc Psychiatry 2001; 40 : $1337-45$.

[29] Ronning J, Handegaard B, Sourander A, Morch W-T. The strengths and difficulties self-reported questionnaire as a screening instrument in Norwegian community samples. Eur Child Adolesc Psychiatry $2004 ; 13: 73$.

[30] Statistics Norway. Population statistics: marriage and divorces. 2014. [Cited: 26 May, 2014]. Available from: https://www.ssb.no/ statistikkbanken/selectvarval/Define.asp? subjectcode $=\&$ ProductId $=\&$ MainTable $=$ SkilsmissAlder $\&$ nvl $=\&$ PLanguage $=0 \&$ nyTmp Var $=$ true \&CMSSubjectArea=befolkning \&KortNavnWeb=ekteskap\& Stat Variant $=\&$ checked $=$ true

[31] Størksen I, Røysamb E, Holmen TL, Tambs K. Adolescent adjustment and well-being: effects of parental divorce and distress. Scand J Psychol 2006; 47: 75-84.

[32] Fröjd S, Marttunen M, Kaltiala-Heino R. The effect of adolescentand parent-induced family transitions in middle adolescence. Nord J Psychiatry 2011; 64: 1-6.

[33] Huurre T, Junkkari H, Aro H. Long-term psychological effects of parental divorce: a follow up study from adolescence to adulthood. Eur Arch Psychiatry Clin Neurosci 2006; 256: 256-63.

[34] Malone PS, Lansford JE, Castellino DR, et al. Divorce and child behavior problems: applying latent change score models to life event data. Struct Equ Modeling 2004; 11(3): 401-23. 
[35] Palosaari U, Aro H. Effect of timing of parental divorce on the vulnerability of children to depression in young adulthood. Adolescence $1999 ; 29(115)$ : 681-91.

[36] McVie S and Holmes L. Family functioning and substance use at ages 12 to 17. The Edinburg Study of Youth Transitions and Crime 2005; 9: 1-35
[37] Allison PD, Furstenberg FF. How marital dissolution affects children: variations by age and sex. Dev Psychol 1989; 25(4): 540-9.

[38] McVie S, Bradshaw P. Adolescent smoking, drinking and drug use. The Edinburg Study of Youth Transitions and Crime 2005; 7: 1-44.

Received: February 26, 2014

Revised: May 28, 2014

Accepted: June 02, 2014

(C) Zeratsion et al.; Licensee Bentham Open.

This is an open access article licensed under the terms of the Creative Commons Attribution Non-Commercial License (http://creativecommons.org/licenses/by-nc/3.0/) which permits unrestricted, non-commercial use, distribution and reproduction in any medium, provided the work is properly cited. 